\title{
AVALIAÇÃO DE MODELOS DE PREDIÇÃO DE PROPRIEDADES MECÂNICAS EM JUNTAS SOLDADAS DE AÇO SAE 1045 POR MEIO DE ENSAIOS MECÂNICOS E MICROSCOPIA*
}

João Paulo Meneguelli Campos ${ }^{1}$

\section{Resumo}

O objetivo deste trabalho foi validar o modelo proposto por Kasuya et al para prever as durezas máximas da zona termicamente afetada (ZTA) em juntas soldadas de um aço com médio teor de carbono através de ensaios empíricos. Para isto, se faz necessário o cálculo da energia de soldagem, quando foram testados modelos apresentados por Marques e Modenesi e também o modelo proposto por Perdigão. As juntas soldadas foram produzidas usando chapas de aço SAE 1045 com espessura de $12,7 \mathrm{~mm}$ como material base, chanfro de $70^{\circ}$ e arame sólido do tipo ER70S-6. Para mudar as condições de resfriamento das juntas soldadas, foram testadas variações nos parâmetros de soldagem, tais como: energia de soldagem, taxa de resfriamento e temperaturas de pré-aquecimento e interpasses. Foram feitos experimentos com e sem pré-aquecimento e testados pós-aquecimento e alívio de tensões. As amostras da zona fundida e da ZTA tiveram as durezas medidas e foram analisadas por meio de microscopia eletrônica de varredura. Em linhas gerais, os resultados empíricos para a dureza na ZTA seguem a mesma tendência prevista pelo modelo de Kasuya et al, mas observam-se desvios na proporcionalidade validando a equação parcialmente para o material estudado. Também foi possível constatar que para o cálculo da energia de soldagem são adequados os modelos propostos por Perdigão e Marques e Modenesi.

Palavras-chave: Soldagem; Zona termicamente afetada; Propriedades mecânicas; Ciclos térmicos.

\section{EVALUATION OF MECHANICAL PROPERTIES' PREDICTION MODELS IN WELDED JOINTS OF SAE 1045 STEEL WITH MECHANICAL TESTING AND MICROSCOPY}

\begin{abstract}
The objective of this study was to evaluate the model proposed by Kasuya et al to predict the maximum hardness in the heat affected zone (HAZ) of welded joints of mediumcarbon steel through empirical tests. For this, it is necessary to calculate the heat input, when were tested models presented by Marques and Modenesi and also the proposed by Perdigão. The welded joints were produced using SAE 1045 steel plates with thickness of $12.7 \mathrm{~mm}$ as base material, 70 chamfer and ER70S-6 solid wire type. To change the cooling conditions of the welded joints were tested variations on welding parameters such as heat input, cooling rate besides preheat and interpass temperatures. Experiments were performed with and without pre-heating and post-heating and stress relieving were tested. Samples of the molten zone and HAZ were hardness measured and evaluated by scanning electron microscopy. In general, the empirical results for the hardness in HAZ follow the same trend as expected by Kasuya et al model, but were observed proportionality deviations partially validating the equation for the studied material. It was also established that for the calculation of heat input, the models proposed by Perdigão and Marques and Modenesi are suitable.
\end{abstract}

Keywords: Welding; Heat affected zone; Mechanical properties; Thermal cycle.

Engenheiro Mecânico, Mestrando em Engenharia Metalúrgica e de Materiais, Especialista em Engenharia Mecânica, Engenharia de Manutenção, ArcelorMittal Tubarão, Serra, ES, Brasil. 


\section{INTRODUÇÃO}

O objetivo deste trabalho foi estudar métodos de predição dos ciclos térmicos e da máxima dureza na zona termicamente afetada (ZTA) de juntas soldadas por arco elétrico de aço médio teor de carbono (SAE 1045) a fim de comparar os valores calculados com os resultados obtidos em ensaios mecânicos. Também foi objetivada a avaliação da do pré-aquecimento e de tratamentos térmicos posteriores à soldagem nas propriedades mecânicas destas juntas soldadas.

As propriedades mecânicas das juntas soldadas dependem de sua constituição microestrutural, além de outras variáveis operatórias, sendo a correlação entre estes fatores um problema complexo [1]. São variáveis operatórias os efeitos de préaquecimento e os tratamentos posteriores à soldagem, que irão compor o ciclo térmico juntamente com a energia de soldagem, além das composições químicas do metal base e do material adicionado.

Para a melhor compreensão do trabalho, serão apresentados tópicos relacionados à energia de soldagem e ciclos térmicos, além da predição da máxima dureza na ZTA, que foram objetos dos modelos matemáticos estudados. Como a lista de equações estudadas neste trabalho é extensa, o formulário total não será citado neste artigo, apenas as equações consideradas mais relevantes em termos de correlação com os ensaios realizados no capítulo de resultados e discussões. Porém, todas as fórmulas podem ser acessadas nas referências citadas no texto.

\subsection{Energia de soldagem e ciclo térmico}

A energia de soldagem é definida como sendo a energia liberada pela fonte de calor por unidade de comprimento da solda. É útil na avaliação dos efeitos metalúrgicos da operação de soldagem de um determinado material. Esta variável pode ser calculada de acordo com as equações disponíveis no trabalho de Marques et al [2]. Um exemplo de efeito metalúrgico relacionado à energia de soldagem é a variação na configuração da microestrutura da zona termicamente afetada, que depende da composição química do material base, da taxa de resfriamento e das tensões aplicadas na soldagem.

A velocidade de resfriamento da junta soldada a uma dada temperatura ou o tempo de resfriamento entre $800^{\circ} \mathrm{C}$ e $500^{\circ} \mathrm{C}$ para aços, que engloba as zonas térmicas de transformações de fases críticas durante o processo de soldagem, é característica importante do ciclo térmico de soldagem, pois influencia fortemente a microestrutura e pode ser estimada pelas equações publicadas por Perdigão [3] em 1982.

Para consideração nas equações dos ciclos térmicos, se faz necessário estimar a espessura crítica que define a condição de transferência de calor entre chapa fina e chapa grossa. Essa estimativa pode ser feita por meio das equações da American Welding Society (AWS) [4] e das equações descritas por Machado [5] em 2000.

\subsection{Predição da dureza máxima na ZTA}

Assim como o indicador Carbono Equivalente, a dureza máxima na ZTA pode ser calculada para também servir de indicador na avaliação da soldabilidade dos aços [7]. Inúmeras fórmulas foram propostas para o cálculo da dureza, de forma particular a máxima dureza da zona termicamente afetada (ZTA) em aços estruturais. No artigo de Marques et al de 2014 [2] são apresentadas equações para predição da dureza máxima na ZTA, assim como disposto em trabalho de Kasuya et al [7] em 1995. 


\section{MATERIAIS E MÉTODOS}

Para o desenvolvimento deste trabalho, foram estudadas chapas com espessura de $12,7 \mathrm{~mm}$ constituídas de material SAE 1045, aço médio teor de carbono com larga aplicação industrial. Os metais de adição foram selecionados para deposição por meio de soldagem por arco elétrico pelo processo GMAW (MIG) com arames sólidos de acordo com a especificação AWS A5.18 classificação ER70S-6, com limite de resistência próximo do metal base adotado a fim de viabilizar uma melhor avaliação das propriedades por meio dos ensaios mecânicos.

Durante a fabricação das juntas soldadas, foram usados diversos parâmetros de soldagem que podem influenciar nas propriedades mecânicas das mesmas. Para cada junta soldadas foram avaliadas as influências combinadas da ausência ou aplicação de pré-aquecimento e a falta ou a adoção de tratamentos térmicos após a soldagem. Para cada junta foi especificado um procedimento de soldagem específico. A tabela 1 resume os parâmetros especificados para as seis experiências analisadas.

Tabela 1. Especificações das combinações de parâmetros variáveis aplicados na soldagem das juntas soldadas estudadas

\begin{tabular}{ccc}
\hline No. & Temperatura de Pré-aquecimento & Tratamento Térmico Posterior \\
\hline $\mathrm{CP}-1$ & Sem pré-aquecimento & Não Aplicado \\
\hline $\mathrm{CP}-2$ & $250^{\circ} \mathrm{C}$ & Não Aplicado \\
\hline $\mathrm{CP}-3$ & Sem pré-aquecimento & Pós Aquecimento $\left(250^{\circ} \mathrm{C}\right)$ \\
\hline $\mathrm{CP}-4$ & $250^{\circ} \mathrm{C}$ & Pós Aquecimento $\left(250^{\circ} \mathrm{C}\right)$ \\
\hline $\mathrm{CP}-5$ & Sem pré-aquecimento & Alívio de Tensões $\left(625^{\circ} \mathrm{C}\right)$ \\
\hline $\mathrm{CP}-6$ & $250^{\circ} \mathrm{C}$ & Alívio de Tensões $\left(625^{\circ} \mathrm{C}\right)$ \\
\hline
\end{tabular}

O chanfro para soldagem foi especificado para resultar em ângulo de $70^{\circ}$ de abertura entre as chapas para as seis combinações a fim de reduzir a sensibilidade a trincas, como especificado na literatura especializada.

Após a preparação das juntas, as chapas foram pré-aquecidas (quando aplicável) e soldadas com o acompanhamento e monitoramento dos parâmetros listados em planilhas de controle para a soldagem da raiz, enchimento e acabamento.

O pré-aquecimento foi realizado por chama direta à temperatura de $250^{\circ} \mathrm{C}$ controlada por lápis de fusão a fim de reproduzir os controles existentes na soldagem industrial.

Posteriormente à deposição da solda, as juntas foram tratadas termicamente conforme as especificações no procedimento de soldagem. O pós-aquecimento foi executado por chama também à temperatura de $250^{\circ} \mathrm{C}$ por 30 minutos logo após 0 último passe de soldagem, seguido de resfriamento lento com o uso de manta térmica.

O alívio de tensões foi obtido em forno para tratamento térmico com controle de temperatura por instrumentação eletrônica. Para isto, as chapas soldadas foram aquecidas à taxa de $200^{\circ} \mathrm{C}$ por hora, mantidas a $625^{\circ} \mathrm{C}$ por 30 min e resfriadas à taxa de $250^{\circ} \mathrm{C}$ por hora em forno. A rastreabilidade das chapas foi garantida com marcações nas peças.

Após as conclusões dos tratamentos térmicos posteriores às soldagens, as juntas foram cortadas nas dimensões especificadas de acordo com a norma técnica ASTM A370 para confecção de corpos de prova para ensaios à tração.

Foram realizados os seguintes ensaios mecânicos e análises microscópicas nos Laboratórios de Testes Mecânicos e Químico da ArcelorMittal Tubarão:

- Ensaio de tração transversalmente ao eixo do cordão de solda;

- Medição de dureza na zona fundida e ZTA; 
- Análise da composição química do metal base por espectrometria ótica;

- Avaliação microestrutural da ZTA por microscopia ótica;

- Análise microestrutural e fractográfica por Microscopia Eletrônica de Varredura (MEV).

\subsection{Modelagem matemática para predição da dureza máxima na ZTA}

Com o objetivo de testar e validar os modelos de predição de dureza estudados, foram analisados os modelos matemáticos apresentados por Marques et al [2] e Kasuya et al [7], possibilitando verificar os que melhor se correlacionam com os processos e materiais aplicados nos experimentos.

Para isto, foram usados os modelos matemáticos para determinação das variáveis dos ciclos térmicos que foram citados no capítulo 1.1, tais como energia de soldagem, tempos e taxas de resfriamento e espessuras críticas das chapas a fim de determinar as condições de transferência de calor a serem consideradas no modelo. Os estudos de Perdigão [3], Machado [5] e as equações especificadas pela AWS [4], além das referências de Marques et al [2], permitiram os cálculos dos parâmetros de ciclos térmicos que alimentaram os modelos de predição de dureza.

\section{RESULTADOS E DISCUSSÃO}

\subsection{Análise das variáveis do processo de soldagem}

Durante o processo de soldagem das chapas para produção das juntas estudadas neste trabalho, foram monitoradas e registradas as principais variáveis de interesse para análise dos comportamentos observados durante os ensaios mecânicos e microestruturais. Os resultados dos levantamentos realizados para os passes de raiz, enchimento e reforço são apresentados nas tabelas 2, 3 e 4, respectivamente, e foram utilizados nos cálculos de modelagem dos ciclos térmicos e de predição da dureza máxima na ZTA.

Tabela 2. Parâmetros de processo levantados durante o passe da raiz da junta soldada.

\begin{tabular}{l|c|c|c|c|c|c}
\hline \multicolumn{1}{c}{ PARÂMETRO } & $\mathbf{C P - 1}$ & $\mathbf{C P - 2}$ & $\mathbf{C P - 3}$ & $\mathbf{C P - 4}$ & $\mathbf{C P - 5}$ & $\mathbf{C P}-\mathbf{6}$ \\
\hline Temperatura de Pré-Aquecimento $\left[{ }^{\circ} \mathrm{C}\right]:$ & 30 & 150 & 30 & 250 & 30 & 250 \\
\hline Tensão [V]: & $17,5-17,8$ & $20,5-20,6$ & $18,5-19,0$ & $18,8-19,0$ & $17,8-18,0$ & $17,5-17,8$ \\
\hline Corrente $[\mathrm{A}]:$ & $92-112$ & $136-152$ & $121-152$ & $120-144$ & $125-140$ & $137-150$ \\
\hline Temperatura de interpasse $\left[{ }^{\circ} \mathrm{C}\right]:$ & 100 & 250 & 150 & 300 & 100 & 300 \\
\hline Quantidade de Passes: & 1 & 1 & 1 & 1 & 1 & 1 \\
\hline Tempo médio de passe [s]: & 50 & 47 & 52 & 52 & 55 & 48 \\
\hline Comprimento médio de passe único $[\mathrm{mm}]:$ & 200 & 200 & 200 & 200 & 200 & 200 \\
\hline
\end{tabular}

Tabela 3. Parâmetros de processo levantados durante os passes de enchimento da junta soldada.

\begin{tabular}{lcccccccc}
\hline \multicolumn{1}{c}{ PARÂMETRO } & CP-1 & CP-2 & CP-3 & CP-4 & CP-5 & CP-6 \\
\hline Tensão [V]: & $22,8-23,0$ & $25,6-25,7$ & $26,7-26,9$ & $26,0-26,1$ & $25,0-25,2$ & $25,7-25,9$ \\
\hline Corrente [A]: & $192-206$ & $208-214$ & $190-218$ & $200-226$ & $201-215$ & $195-215$ \\
\hline Temperatura de interpasse [ $\left.{ }^{\circ} \mathrm{C}\right]:$ & $150-250$ & $250-320$ & $300-350$ & $350-400$ & $250-350$ & $300-350$ \\
\hline Quantidade de Passes: & 3 & 3 & 3 & 3 & 3 & 3 \\
\hline Tempo médio de passe [s]: & 45 & 38 & 34 & 39 & 46 & 45 \\
\hline Comprimento médio de passe único [mm]: & 200 & 200 & 200 & 200 & 200 & 200 \\
\hline
\end{tabular}


Tabela 4. Parâmetros de processo levantados durante os passes de acabamento da junta soldada e tratamentos térmicos posteriores.

\begin{tabular}{|c|c|c|c|c|c|c|}
\hline PARÂMETRO & CP-1 & CP-2 & CP-3 & CP-4 & CP-5 & CP-6 \\
\hline Tensão [V]: & $23,7-23,9$ & $23,6-23,9$ & $25,7-25,9$ & $25,9-26,1$ & $24,8-25,0$ & $25,7-25,6$ \\
\hline Corrente $[A]$ : & $209-218$ & $193-207$ & $200-212$ & $208-229$ & $218-242$ & $208-223$ \\
\hline Temperatura de interpasse $\left[{ }^{\circ} \mathrm{C}\right]:$ & $150-250$ & $320-350$ & 400 & 350 & $320-350$ & 350 \\
\hline Quantidade de Passes: & 3 & 3 & 3 & 3 & 3 & 3 \\
\hline Tempo médio de passe [s]: & 36 & 36 & 32 & 32 & 32 & 30 \\
\hline Comprimento médio de passe único [mm]: & 200 & 200 & 200 & 200 & 200 & 200 \\
\hline Tratamento Térmico: & - & - & $\begin{array}{c}\text { Pós- } \\
\text { aquecimento }\end{array}$ & $\begin{array}{c}\text { Pós- } \\
\text { aquecimento }\end{array}$ & $\begin{array}{l}\text { Alívio de } \\
\text { Tensões }\end{array}$ & $\begin{array}{l}\text { Alívio de } \\
\text { Tensões }\end{array}$ \\
\hline Taxa de aquecimento $\left[{ }^{\circ} \mathrm{C} / \mathrm{h}\right]:$ & - & - & - & - & 200 & 200 \\
\hline Temperatura de encharque $\left[{ }^{\circ} \mathrm{C}\right]$ : & - & - & 250 & 250 & 625 & 625 \\
\hline Tempo de encharque [min]: & - & - & 30 & 30 & 30 & 40 \\
\hline Método de resfriamento: & Ar calmo & Ar calmo & Manta térmica & Manta térmica & Forno & Forno \\
\hline Taxa de resfriamento $\left[{ }^{\circ} \mathrm{C} / \mathrm{h}\right]$ : & - & - & - & - & 250 & 250 \\
\hline
\end{tabular}

Foram analisadas as influências das cargas térmicas transferidas por meio do préaquecimento e energia de soldagem nas configurações microestruturais e propriedades mecânicas resultantes. Para tal, foram aplicadas equações para estimativa das energias de soldagem, tempos de resfriamentos e para predição de valores de dureza alcançados após os passes para deposição da raiz, do enchimento e do acabamento da junta soldada.

Os valores de energia líquida de soldagem foram obtidos por meio da equação 1 , sendo considerado o rendimento de 0,75 para o processo GMAW (MIG).

$$
H_{L}=\eta \cdot \frac{V \cdot I}{v}(1)
$$

Legenda: H: energia e soldagem $(\mathrm{J} / \mathrm{cm})$; V: tensão de soldagem $(\mathrm{V})$; I: corrente de soldagem (A); v: velocidade de soldagem $(\mathrm{cm} / \mathrm{s})$; $\eta$ : rendimento do processo de soldagem.

Os resultados dos cálculos de energia líquida de soldagem são apresentados na figura 1. Observa-se no gráfico um maior aporte térmico nos passes do enchimento. Isto favorece a condição de resfriamento $e$, consequentemente, a formação de microestruturas menos duras na ZTA desta porção da solda.

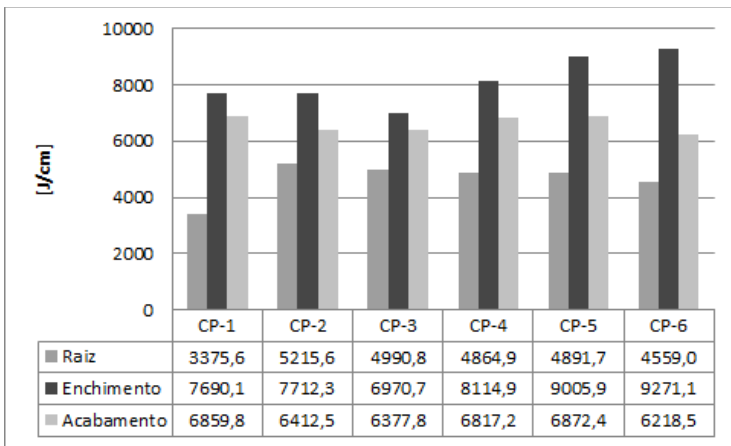

Figura 1. Energias líquidas de soldagem estimadas para os passes da raiz, enchimento e acabamento das juntas soldadas.

Para todas as juntas soldadas, a condução de calor considerada foi a de chapa fina, com passe de penetração, fonte de energia linear e fluxo de calor bidimensional.

Esta condição foi verificada para cada passe de raiz, condição de menor aporte térmico, sendo a condição mais crítica para este processo de transferência de calor. 
Para os demais passes, com maior aporte de energia na soldagem, a relação se torna ainda mais favorável à definição da condição de chapa fina.

Os tempos de resfriamento previstos entre $800^{\circ} \mathrm{C}$ e $500^{\circ} \mathrm{C}$, faixa que engloba a transformação austenítica, também foram calculados a partir da equação 2 , proposta por Perdigão [3] para chapas finas e que apresentou resultados mais coerentes entre os experimentos e os cálculos, considerando as propriedades físicas do metal de adição e as energias líquidas calculadas para as seis juntas soldadas. A figura 2 expõe os tempos calculados para as porções das soldas das chapas analisadas.

$$
\left(\Delta t_{8 / 5}\right)_{f}=\frac{H_{L}^{2}}{2 \cdot \pi \cdot k \cdot \rho \cdot C \cdot h^{2}} \cdot\left(\frac{1}{\left(500-T_{0}\right)^{2}}-\frac{1}{\left(800-T_{0}\right)^{2}}\right)
$$

Legenda: $(\Delta \mathrm{t} / 5) \mathrm{f}$ : tempo de resfriamento entre 800 e $500{ }^{\circ} \mathrm{C}$ em [s], para a condição de chapa fina; $\mathrm{H}_{\mathrm{L}}$ : energia líquida de soldagem em $[\mathrm{J} / \mathrm{cm}] ; \mathrm{k}$ : condutividade térmica do material em $\left[\mathrm{J} /\left(\mathrm{cm} \cdot \mathrm{s} \cdot{ }^{\circ} \mathrm{C}\right)\right]$; $\rho$ : densidade do material em $\left[\mathrm{g} / \mathrm{cm}^{3}\right]$; C: calor específico do material em $\left[\mathrm{J} /\left(\mathrm{g} \cdot{ }^{\circ} \mathrm{C}\right)\right]$; $\mathrm{h}$ : espessura da peça em $[\mathrm{mm}] ; \mathrm{T}_{0}$ : temperatura inicial da chapa em $\left[{ }^{\circ} \mathrm{C}\right]$.

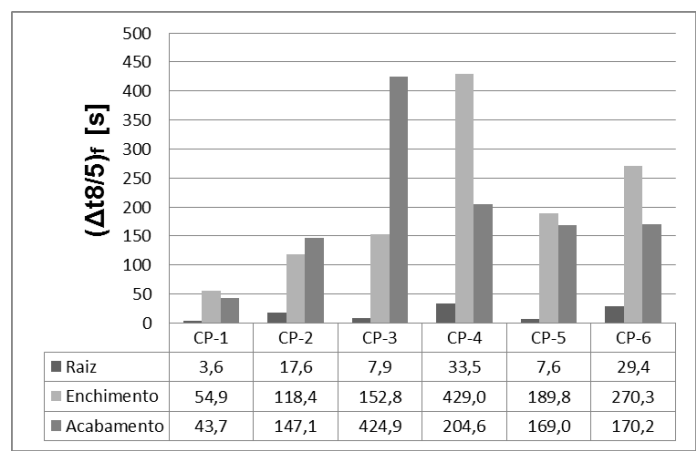

Figura 2. Tempos de resfriamento entre $800^{\circ} \mathrm{C}$ e $500^{\circ} \mathrm{C}$ calculados para as porções das soldas.

Dentre os modelos avaliados, verificou-se que o modelo de Kasuya et al [7] (equações 3 e 4) mostrou maior coerência com os experimentos realizados para 0 material estudado frente aos resultados obtidos nos experimentos.

$$
\begin{array}{r}
H V_{M a ́ x}=\frac{H_{M}+H_{B}}{2}-\frac{H_{M}-H_{B}}{2,2} \cdot \arctan (\boldsymbol{x}) \\
x=4 \cdot \frac{\log \left(\Delta t_{8 / 5} / t_{M}\right)}{\log \left(t_{B} / t_{M}\right)}-2(4)
\end{array}
$$

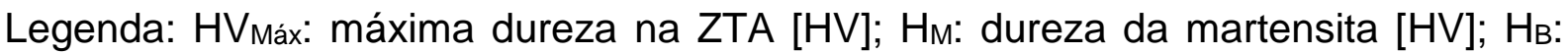
dureza da bainita $[\mathrm{HV}]$; $t_{\mathrm{M}}$ : tempo requerido para transformação total em martensite [s]; tB: tempo requerido para transformação total em bainita [s].

Com base nos cálculos das equações 3 e 4, plotou-se o gráfico apresentado na figura 3a, que demonstra a maior dureza nos passes de raiz em função dos menores tempos de resfriamento (como observado na figura 2). O CP-1 resultou em dureza próxima à martensita pura estimada para o material base, mensurada em $678 \mathrm{HV}$. A dureza média para cada junta soldada foi ponderada na quantidade de passes para cada etapa e, comparativamente, observaram-se valores maiores para as juntas soldadas sem pré-aquecimento. Este item reforça a tese de maior fragilidade na ZTA de materiais soldados sem pré-aquecimento. 
As durezas calculadas foram convertidas em valores de resistência mecânica a fim de permitir a estimativa desta importante propriedade e serem comparadas com os ensaios mecânicos. Para isto, a equação 5 [10] foi utilizada. O gráfico mostrado na figura $3 b$ revela uma tendência de diminuição das magnitudes das propriedades mecânicas avaliadas em função do aumento da energia de soldagem, sem considerar os efeitos dos tratamentos térmicos posteriores.

$$
R_{m}=3 \cdot \mathrm{HV}_{M \mathrm{ÁX}}+22,3
$$

Legenda: Rm: Resistência mecânica na ZTA [Mpa]; HVMÁx: dureza máxima calculada na ZTA [HV].
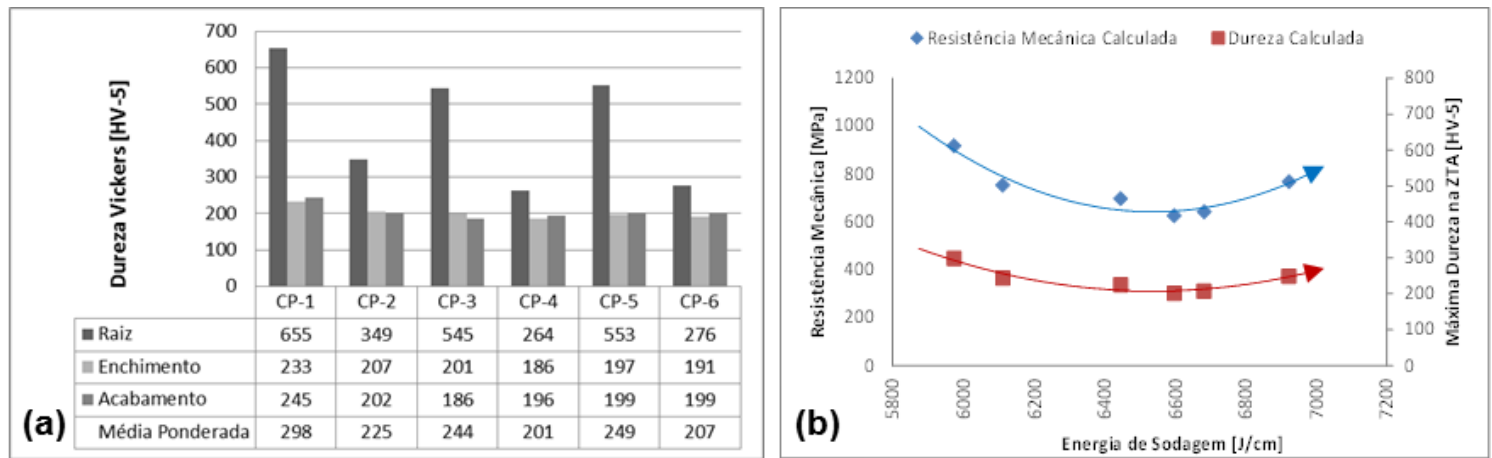

Figura 3. Comparativo de durezas calculadas e medidas: (a) com base nos parâmetros dos processos de soldagem das juntas avaliadas; (b) indicando comportamentos similares de durezas e resistências mecânicas em relação à energia de soldagem.

\subsection{Ensaios mecânicos dos materiais}

As medições de dureza dispostas na tabela 5 mostram valores correlatos com os calculados para a ZTA, como pode ser verificado na figura 4. Os corpos de prova que receberam pós-aquecimentos (CP-3 e CP-4) se apresentam de forma errática (pontos vermelhos) em função do pós-aquecimento, alterando a taxa de resfriamento após soldagem destas juntas soldadas. Plotando a curva teórica de dureza em função do tempo de resfriamento (vide figura $5 \mathrm{a}$ ), se pode verificar a dispersão dos valores calculados e medidos dentro do comportamento esperado pelo modelo analisado. Os resultados de Kasuya et al [7] para aços baixo carbono são mostrados em gráfico similar na figura $5 b$.

Tabela 5. Resultados de dureza realizados na zona fundida, ZTA e Metal Base.

\begin{tabular}{c|c|c|c}
\hline \multirow{2}{*}{ Amostra } & \multicolumn{3}{c}{ Dureza [HV] } \\
\cline { 2 - 4 } & Zona Fundida & ZTA & Metal Base \\
\hline CP-1 & 237 & 254 & 241 \\
\hline CP-2 & 204 & 226 & 195 \\
\hline CP-3 & 197 & 246 & 215 \\
\hline CP-4 & 207 & 244 & 214 \\
\hline CP-5 & 217 & 234 & 211 \\
\hline CP-6 & 214 & 220 & 222 \\
\hline
\end{tabular}




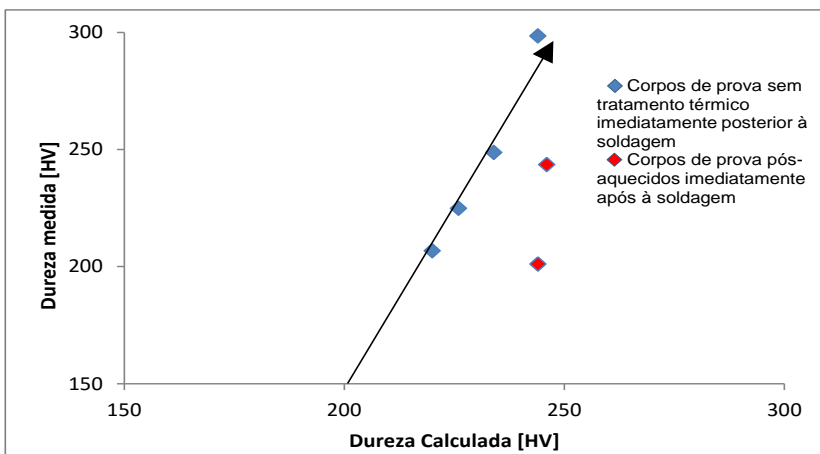

Figura 4. Gráfico de correlação entre durezas calculadas e medidas para a ZTA.
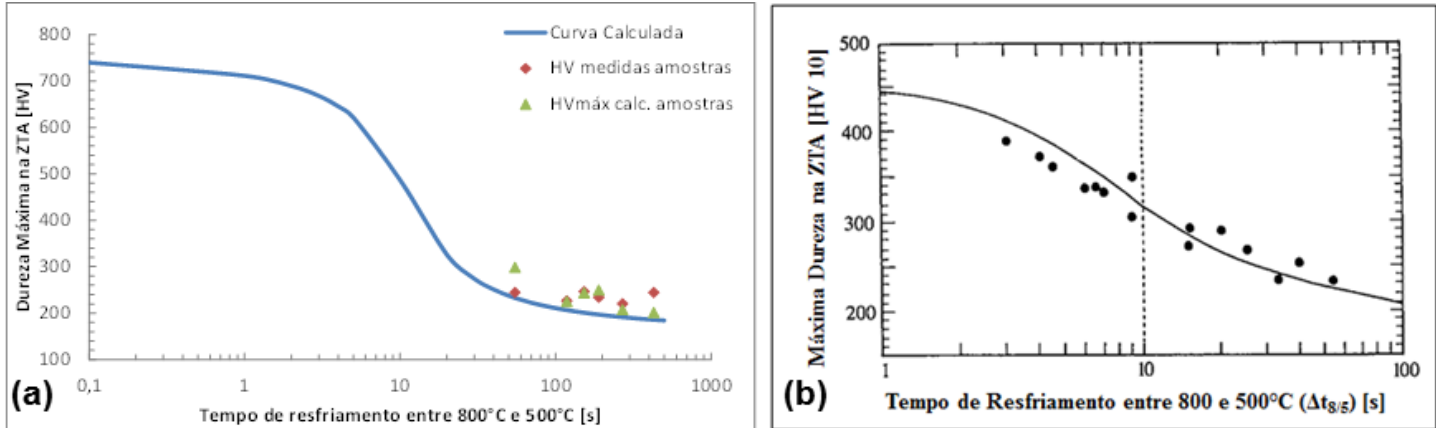

Figura 5. (a) Comparação dos valores medidos e calculados de dureza na ZTA das juntas soldadas analisadas neste trabalho; (b) Gráfico de correlação entre durezas calculadas e medidas para a ZTA dos corpos de prova estudados por Kasuya et al [7].

A fim de se comprovar a relação da dureza da ZTA com o tempo de resfriamento entre $800^{\circ} \mathrm{C}$ e $500^{\circ} \mathrm{C}$, a figura 6a reúne os dados calculados e medidos e permite a constatação de que a dureza diminui com um maior tempo de resfriamento. $O$ trabalho de Reis Sobrinho et al de 2007 [9] para aços de alta resistência e baixa liga (ARBL) também permite esta confirmação por meio da compilação de seus dados, como disposto na figura $6 \mathrm{~b}$.
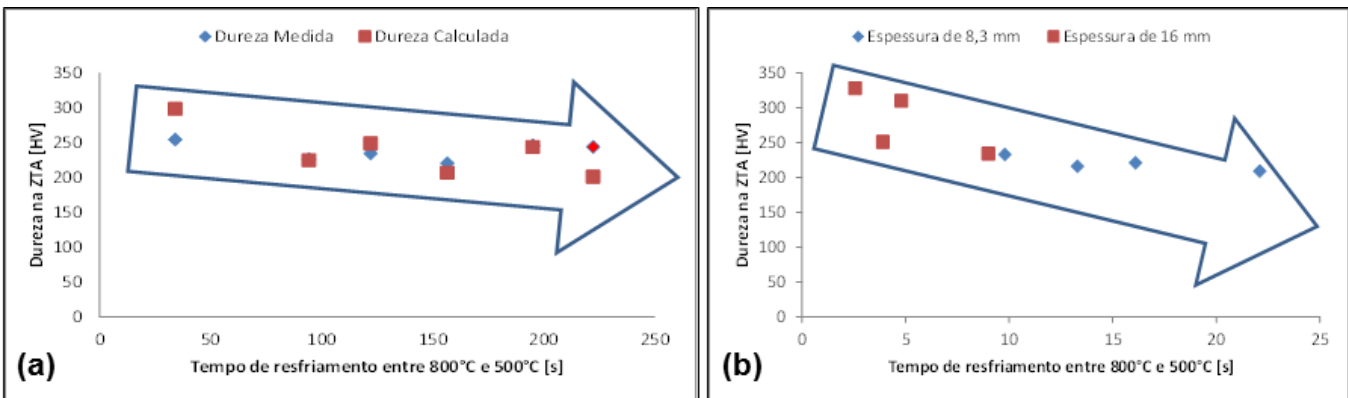

Figura 6. (a) Gráfico de correlação das durezas medidas e calculadas para a ZTA com tempos de resfriamentos calculados; (b) Gráfico construído a partir de dados extraídos do trabalho de Reis Sobrinho et al [9] correlacionando as durezas dos materiais medidos na ZTA com os tempos de resfriamentos calculados.

Em relação aos ensaios de tração, três dos seis corpos de prova romperam na região da solda e os demais foram fraturados no metal base em posições similares. A tabela 6 lista os principais resultados obtidos dos ensaios. 
Tabela 6. Resumo dos ensaios de tração dos corpos de prova soldados transversalmente

\begin{tabular}{l|c|c|c}
\hline Amostra & $\begin{array}{c}\text { Limite de Escoamento } \\
{[\mathrm{MPa}]}\end{array}$ & $\begin{array}{c}\text { Limite de Resistência } \\
{[\mathrm{MPa}]}\end{array}$ & $\begin{array}{c}\text { Alongamento } \\
{[\%]}\end{array}$ \\
\hline $\mathrm{CP}-1$ & 385 & 593 & 6 \\
\hline $\mathrm{CP}-2^{*}$ & 336 & 547 & 18 \\
\hline $\mathrm{CP}-3^{*}$ & 332 & 556 & 19 \\
\hline $\mathrm{CP}-4$ & 357 & 563 & 11 \\
\hline $\mathrm{CP}-5^{*}$ & 330 & 532 & 18 \\
\hline $\mathrm{CP}-6$ & 320 & 483 & 7 \\
\hline
\end{tabular}

$\left({ }^{*}\right)$ Corpos de prova não romperam na solda.

Os resultados dos ensaios de tração mostram pequena correlação com todos os valores calculados, como pode ser observado na figura 7. Desconsiderando os corpos de provas CP-3 e CP-4 (pontos vermelhos), que sofreram suavizações nas curvas de resfriamento a partir de $250^{\circ} \mathrm{C}$ em função do pós-aquecimento, se obtém uma correlação maior. Porém, com desvio de magnitude em média de $218 \mathrm{MPa}$ em relação aos valores calculados. Deve ser ressaltado que os corpos de provas CP-2, CP-3 e CP-5 não romperam na solda e resistiriam a tensões superiores às registradas após fraturas nos ensaios realizados, contribuindo para o desvio de correlação verificado.

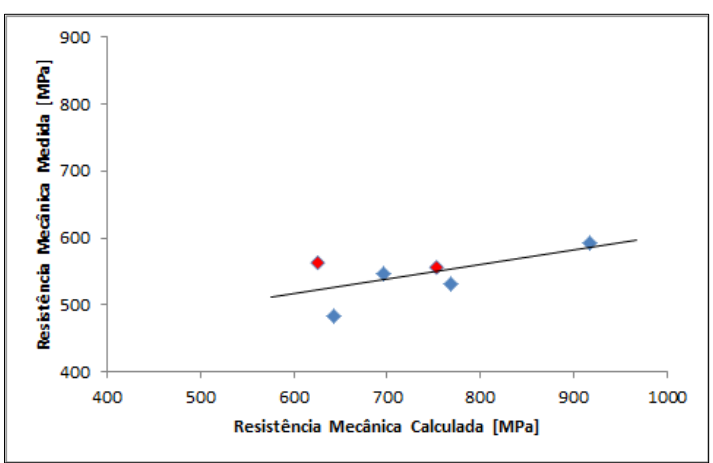

Figura 7. Correlação entre valores de resistência estimados e resultantes nos ensaios de tração.

A figura 8a apresenta a comparação entre as resistências mecânicas calculadas e medidas, além dos limites de escoamento obtidos nos ensaios de tração em função das temperaturas dos tratamentos posteriores aplicados. As curvas mostram tendências de redução das magnitudes dos parâmetros analisados com o aumento das temperaturas dos tratamentos térmicos aplicados. Este comportamento é similar aos dados do trabalho apresentado por Taniguchi e Yamashita (2012) [8], como pode ser comparado na figura $8 \mathrm{~b}$.
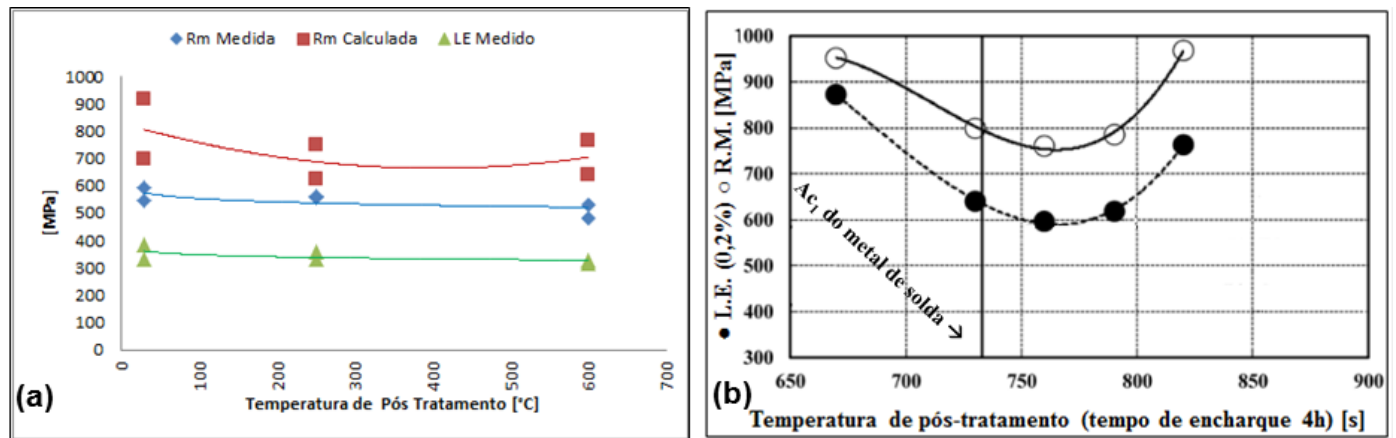

Figura 8. (a) Gráfico comparando as resistências mecânicas calculadas, obtidas e limites de escoamentos medidos em relação às temperaturas de tratamentos posteriores aplicados; (b) Curvas de limites de escoamento e resistências mecânicas de um aço carbono com alto teor de cromo submetido a tratamentos térmicos posteriores à soldagem [8]. 
Por meio de avaliações macro e microscópicas, pode-se constatar que as amostras que não foram submetidas ao pré-aquecimento (CP-1, CP-3 e CP-5) apresentaram vazios em suas zonas fundidas. As amostras submetidas a tratamentos de alívio de tensões (CP-5 e CP-6) exibiram as menores extensões de suas respectivas zonas termicamente afetadas. Estes aspectos influenciaram as variações de propriedades mecânicas em relação aos valores calculados devido ao refino de grãos ou pela inserção de defeitos microestruturais.

\section{CONCLUSÃO}

O modelo matemático para prever a dureza máxima da zona termicamente afetada proposto por Kasuya et al mostrou-se adequado e segue a mesma tendência dos resultados empíricos. Porém, apresenta desvios na proporcionalidade para o material estudado (aço médio carbono).

Os resultados dos corpos de prova soldados submetidos ao pós-aquecimento exibem maiores desvios de correlação entre os valores calculados e os obtidos nos ensaios de dureza e de tração em relação aos demais. Isto ocorre em função destes espécimes serem submetidos à menor taxa de resfriamento após soldagem, restringindo a aplicação dos modelos estudados nestes casos.

A aplicação de tratamentos posteriores à soldagem provoca distorções nas durezas resultantes dos materiais em relação aos valores calculados. No caso do pósaquecimento a suavização da curva de resfriamento a temperaturas inferiores a $500^{\circ} \mathrm{C}$ não seriam consideradas pelas equações estabelecidas nos modelos avaliados. Já o tratamento para alívio de tensões tende a promover alterações na microestrutura da zona termicamente afetada influenciando na dureza desta porção do material, diferindo dos valores medidos, como observado neste trabalho. Portanto, nestes casos a aplicação dos modelos analisados apresentará imprecisão. Finalmente, a utilização das equações selecionadas neste trabalho previamente à elaboração de procedimentos de soldagem pode ajudar na predição de propriedades mecânicas e proporcionar um controle mais rigoroso do processo de soldagem durante a execução, conferindo maior qualidade, segurança e redução de custos na aplicação desta tecnologia.

\section{Agradecimentos}

Agradeço o apoio e ensinamentos do PROPEMM (IFES) e a estrutura e recursos disponibilizados pela ArcelorMittal Tubarão para o desenvolvimento deste trabalho.

\section{REFERÊNCIAS}

1 MODENESI, P. J. Soldabilidade dos Aços Transformáveis. Belo Horizonte: UFMG; 2010.

2 MARQUES, P. V., MODENESI, P. J. Algumas Equações Úteis em Soldagem. Soldagem \& Inspeção. 2014; 19: 91-102.

3 PERDIGÃO, S. C. Ciclos térmicos de soldagem. Metalurgia ABM. 1982; 38 (295): 349353.

$4 \quad$ AWS. Welding Handbook: Welding Technology. Vol.1. 9aㅡ Ed. Miami: American Welding Society; 2001.

5 MACHADO, I. G. Condução de calor na soldagem: Fundamentos \& Aplicações. Porto Alegre: Imprensa Livre Editora; 2000. 
6 ION, J. C.; ASHBY, M. F. Weldability charts for constructional steels. 6th EEIGM International Conference Advanced Materials Research: 7th and 8th November, 2011 EEIGM, Nancy, France. I O P Conference Series: Materials Science and Engineering. IOP Publishing Ltd. 2012; 31 (012011): 1-7.

7 KASUYA, T, YURIOKA, N., OKUMURA, M. Methods for Predicting Maximum Hardness of Heat-Affected Zone and Selecting Necessary Preheat Temperature for Steel Welding. Nippon Steel Technical Report. 1995; (65): 7-14.

8 TANIGUCHI, G.; YAMASHITA, K. Effects of Post Weld Heat Treatment (PWHT) Temperature on Mechanical Properties of Weld Metals for High-Cr Ferritic Heat Resistant Steel. Kobelco Technology Review. 2013; (32): 33-39.

9 REIS SOBRINHO, J. F.; ALCÂNTARA, N. G. Análise dos ciclos térmicos obtidos na zona afetada termicamente da junta soldada de um aço de alta resistência. Il Congr. de Pesq. e Inovação da Rede Norte Nordeste de Educ. Tecnológica. 2007; Anais: 1-10.

10 YURIOKA, N.; KOJIMA, K. A predictive formula of weld metal tensile strength. Quarterly Journal of the Japan Welding Society. 2004; 22(3): 53-60. 